\title{
Volumetric capnography: In the diagnostic work-up of chronic thromboembolic disease
}

\author{
This article was published in the following Dove Press journal: \\ Vascular Health and Risk Management \\ 15 May 2010 \\ Number of times this article has been viewed
}

\author{
Marcos Mello Moreira' \\ Renato Giuseppe Giovanni \\ Terzi ${ }^{1}$ \\ Laura Cortellazzi ${ }^{2}$ \\ Antonio Luis Eiras Falcão' \\ Heitor Moreno Junior ${ }^{2}$ \\ Luiz Cláudio Martins ${ }^{2}$ \\ Otavio Rizzi Coelho \\ 'Department of Surgery, ${ }^{2}$ Department \\ of Internal Medicine, State University \\ of Campinas, School of Medical \\ Sciences, Campinas, Sao Paulo, Brazil
}

Correspondence: Marcos Mello Moreira Rua Celso Egídio de Souza Santos, 18I, Jardim Chapadão, CEP: 13070-057, Campinas, São Paulo, Brazil

$\mathrm{Tel}+55$ I9 324| 9872

Fax +55 1935217830

Email tucammm@yahoo.com.br

\begin{abstract}
The morbidity and mortality of pulmonary embolism (PE) have been found to be related to early diagnosis and appropriate treatment. The examinations used to diagnose PE are expensive and not always easily accessible. These options include noninvasive examinations, such as clinical pretests, ELISA D-dimer (DD) tests, and volumetric capnography (VCap). We report the case of a patient whose diagnosis of PE was made via pulmonary arteriography. The clinical pretest revealed a moderate probability of the patient having PE, and the DD result was negative; however, the VCap associated with arterial blood gases result was positive. The patient underwent all noninvasive exams following admission to hospital and again eight months after discharge. Results gained from invasive tests were similar to those produced by image exams, highlighting the importance of VCap as an important noninvasive tool.
\end{abstract}

Keywords: pulmonary embolism, pulmonary hypertension, volumetric capnography, d-dimers, pretest probability

Pulmonary embolism (PE) is the third most common cause of death in the United States, with an estimated 100,000 deaths and over 780,000 clinically apparent cases diagnosed annually. ${ }^{1}$ Results of autopsy studies have indicated that most cases of venous thromboembolism (VTE) go undiagnosed, even when they are the immediate cause of death. When PE is missed on initial presentation, a delay of 24 hours, during which anticoagulation occurs, increases the risk of recurrent embolism from $4 \%$ to $23 \%$, and leads to a fivefold increase in the likelihood of death within a year. ${ }^{2}$ Traditional examinations used to detect PE are generally expensive and are not able to be carried out in all hospitals, which increases difficulty of access.

In the search for a cost-effective screening approach to PE, ELISA D-dimer (DD) testing shows promise, often sparing patients unnecessary radiation and expense. However, DD has limitations, and gaining an understanding of these limitations in practice is vital. Additionally, measuring the volumetric capnography (VCap) associated with arterial blood gas analysis (ABGA), is an alternative to traditional examinations.

In this case report we present the results of clinical score (Wells), DD (Vidas ${ }^{\circledR}$ ), and the VCap variables of a patient diagnosed with PE who was submitted for clinical treatment (dicoumarin). The DD, VCap, and image exams were conducted following admission to the hospital and again eight months after discharge (Table 1). submit your manuscript $\mid$ www.dovepress.com

Dovepress

9160 


\section{Case report}

Our case study was a 25 -year-old male smoker, who had symptoms of medium level dyspnea for one year. He was sent to a referral center for further investigation and underwent a transthoracic echocardiogram, which revealed "straddling thrombus", or a moderate dilation of the chambers on the right side of the heart; additionally, his pulmonary artery systolic pressure was estimated at $78 \mathrm{mmHg}$ and pulmonary artery diastolic pressure was estimated at $22 \mathrm{mmHg}$. Following the transthoracic echocardiogram, he was admitted to hospital based on a preliminary diagnosis of PE and treatment of anticoagulation with heparin was started.

In the physical examination the patients was found to be in generally good health. He was conscious, alert, dyspneic (22 bpm), had cyanosis of the extremities, a heart rate 88 , arterial pressure of $150 / 110 \mathrm{mmHg}$, and did not have edema or tightening of the lower limbs. A pretest (Wells' score) revealed there was a moderate probability that the patient had PE. ABGA in room air revealed $\mathrm{PaO}_{2}=66.2$; $\mathrm{PaCO}_{2}=28.9 \mathrm{mmHg}$; and $\mathrm{SpO}_{2}=98 \%$.

Pulmonary scintigraphy showed heterogeneous distribution of perfusion in both lungs.

The ELISA DD levels were determined (VIDAS ${ }^{\circledR} \mathrm{D}$-dimer; bioMérieux, France); this test has a cutoff of $<500 \mathrm{ng} / \mathrm{mL}$. The sample taken on admission to the hospital was negative for $\mathrm{PE}$ (339.54 ng/mL; false-negative). The Doppler echocardiogram of the lower limbs showed no thrombi.

Respiratory dead space and functional space were determined through VCap $\left(\mathrm{CO}_{2} \mathrm{SMO}\right.$ PLUS $8100^{\circledR}$; Dixtal/ Novametrix, Brazil) associated with ABGA (Radiometer $\mathrm{ABL}^{\circledR} 700$ Series; Radiometer Medical ApS, Denmark). The indices derived from these values were the end-tidal alveolar dead space fraction (AVDSf), the late dead space fraction (fDlate), and arterial-end-tidal $\mathrm{CO}_{2}$ gradient $\left[\mathrm{P}(\mathrm{a}-\mathrm{et}) \mathrm{CO}_{2}\right]$ (Table 1).

After a history of more than two weeks of development and maintaining clinical and hemodynamic stability, we suspected repeated and extensive PE, but chemical thrombolysis did not show improvement. A pulmonary arteriogram revealed

Table I VCap variables in admission and follow-up

\begin{tabular}{lllll}
\hline & D-Dimer & AVDSf & fDLate & $\begin{array}{l}\mathbf{P}(\text { a-et }) \mathbf{C O}_{2} \\
(\mathbf{m m H g})\end{array}$ \\
\hline Cut-off & $<500 \mathrm{ng} / \mathrm{mL}$ & 0.15 & 0.12 & 5.0 \\
Admission & $339.54 \mathrm{ng} / \mathrm{mL}$ & 0.42 & 0.38 & 12.0 \\
Post-8 months & $157.96 \mathrm{ng} / \mathrm{mL}$ & 0.34 & 0.31 & 10.2 \\
\hline
\end{tabular}

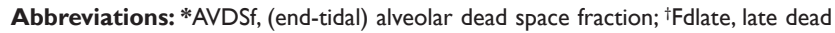
space fraction; $¥ \mathrm{P}\left(\mathrm{a}\right.$-et) $\mathrm{CO}_{2}$, arterial-end-tidal gradient of $\mathrm{CO}_{2}$. the patient had normal coronary arteries; ventriculography showed an ejection fraction of LV of $69 \%$; important bulging in the abdominal region; amputation was present in peripheral branches, suggestive of multiple chronic emboli; and thrombus was located in the inferior lobe of the left lung, along with hypoperfusion of the middle segment in the lung right.

Eight months after the patient was discharged, a new lung scintigraphy (control), ELISA DD, and VCap were carried out. In comparison with the first round of tests, this scintigraphy revealed a discreet improvement in the perfusion pattern in the apical, anterior, posterior, and superior segments of the patient's right lung. The DD result was $157.96 \mathrm{ng} / \mathrm{mL}$. The ABGA in room air revealed $\mathrm{PaO}_{2}=70.0 \mathrm{mmHg}$, $\mathrm{PaCO}_{2}=30.0 \mathrm{mmHg}$, and $\mathrm{SpO}_{2}=99 \%$.

The association of VCap variables with ABGA allows for the calculation of several indices, the variations of which can infer the presence of occlusion or improve after treatment of pulmonary vessels..$^{3-5}$

We determined the following parameters:

- AVDSf: $\mathrm{PaCO}_{2}-\mathrm{PetCO} 2 / \mathrm{PaCO}_{2}{ }^{6}$

- $\quad$ fDlate $=\mathrm{PaCO}_{2}-\mathrm{Pet}(15 \% \mathrm{CPT}) \mathrm{CO}_{2} / \mathrm{PaCO}_{2},{ }^{7}$

- $\mathrm{P}\left(\mathrm{a}\right.$-et) $\mathrm{CO}_{2}: \mathrm{PaCO}_{2}-\mathrm{PetCO}_{2}{ }^{8}$

The calculation of fDlate attempts to avoid differences introduced in the functional dead space value by height, gender, and age. The use of an estimated tidal volume also eliminates the effect of the respiratory rate on tidal volume. In addition, the mathematical extrapolation of phase III of the $\mathrm{CO}_{2}$ expirogram at $15 \%$ of the total lung capacity (TLC) is aimed at bringing $\mathrm{PetCO}_{2}$ and $\mathrm{PaCO}_{2}$ into closer proximity. The TLC was obtained using the method devised by Grimby et al. ${ }^{9}$

\section{Discussion}

When an episode of PE occurs, the imbalance in the ventilation/perfusion ratio is increased, and, consequently, the variables which form the functional dead space are altered. In the literature, we observe the following higher cut-off values for the studied variables: 0.15 for AVDSf, ${ }^{6} 0.12$ for fDlate, ${ }^{7}$ and $5 \mathrm{mmHg}$ for $\mathrm{P}(\mathrm{a}$-et $) \mathrm{CO}_{2} \cdot{ }^{8}$ Considering the fact that a higher calculated value indicates greater obstruction of the vascular system (and a larger alveolar dead space), we infer that there is a correlation between the extent of the area without perfusion and the value obtained..$^{3-5}$ In this patient, the result of VCap variations were displayed in imaging results.

Breen et $\mathrm{al}^{10}$ in a similar case report, albeit without follow-up and VCap, described a patient with acute PE with a similarly negative ELISA DD result (495.1 ng/mL). 
Ray et $\mathrm{al}^{11}$ using the same methodology ELISA (VIDAS ${ }^{\circledR}$ ), obtained 12 false-negative results for patients with DVT or PE interned in emergency services. So, in rare cases where the symptoms are present over a long period of time, D-dimers might have become negative. However, results of our study show that there is an attenuate for this situation: the association of a clinical pre-test + DD with VCap. Again, it should be emphasized that the association of noninvasive exams is essential (enhance sensibility).

It is known that when dealing with PE, anticoagulation is aimed at reducing the possibility of a new embolic phenomenon, as well as reducing the mortality risk. Therefore, imaging tests are requested whenever there is clinical suspicion of PE. In spite of the fact that the diagnostic work-up for chronic $\mathrm{PE}$ is not the same as that for acute PE, noninvasive methods that rule out the possibility of PE would reduce the number of patients unnecessarily undergoing imaging tests.

\section{Conclusions}

In summary, we have presented the case of a patient with diagnosis of PE, which was confirmed through imaging tests and with altered pulmonary functional variables obtained through VCap tests. These variables followed the results of image exams throughout clinical intervention, highlighting the importance of VCap as a potential noninvasive tool when used in association with measures of DD levels and clinical pretests. In rare situations, in patients with clinical pretest result suggesting moderate or high probability for $\mathrm{PE}$, but with a negative DD result, an alternative test could be the VCap. Our results indicate it must be performed twice because in our case study the first time it paralleled the important vascular obstruction, and the second time it showed the absence of improvement. In this way we have demonstrated that VCap is a very interesting noninvasive tool to appreciate the vascular obstruction of a chronic thromboembolic disease.

\section{Acknowledgments}

This study received part of its funding in the form of a grant from the Fundação de Amparo a Pesquisa do Estado de São Paulo (FAPESP, Foundation for the Support of Research in the State of São Paulo; Grant no. 02/05252-3).

\section{Disclosures}

The authors report no conflicts of interest in this work.

\section{References}

1. Horlander KT, Mannino DM, Leeper KV. Pulmonary embolism mortality in the United States, 1979-1998: an analysis using multiple-cause mortality data. Arch Intern Med. 2003;163:1711-1717.

2. Kline JA, Runyon MS. Pulmonary embolism and deep venous hrombosis. In: Marx JA, Hockberger RS, Walls RM, Eds. Rosen's emergency medicine. St. Louis, MO: CV Mosby, Inc.; 2002:1210-1234.

3. Moreira MM, Terzi RGG, Vieira RW, et al. Pre and post-pulmonary thromboendarterectomies capnographic variables. Rev Bras Cir Cardiovasc. 2007;24:509-512.

4. Moreira MM, Terzi RGG, Pereira MC, Grangeia TAG, Paschoal IA. Volumetric capnography as a noninvasive diagnostic procedure in acute pulmonary thromboembolism. J Bras Pneumol. 2008;34:328-332.

5. Moreira MM, Terzi RGG, Carvalho CHN, Oliveira Neto AF, Pereira MC, Paschoal IA. Alveolar dead space and capnographic variables before and after thrombolysis in patients with acute pulmonary embolism. Vasc Health Risk Manag. 2009;5:9-12.

6. Rodger MA, Bredeson CN, Jones G, et al. The bedside investigation of pulmonary embolism diagnosis study. Arch Intern Med. 2006;166: 181-187.

7. Eriksson L, Wollmer P, Olsson CG, et al. Diagnosis of pulmonary embolism based upon alveolar dead space analysis. Chest. 1989;96: $357-362$.

8. Fletcher R, Jonson B, Cumming G, Brew J. The concept of deadspace with special reference to the single breath test for carbon dioxide. $\mathrm{Br} \mathrm{J}$ Anaesth. 1981;53:77-88.

9. Grimby G, Söderholm B. Spirometric studies in normal subjects. III. Static lung volumes and maximum voluntary ventilation in adults with a note on physical fitness. Acta Med Scand. 1963;173:199-206.

10. Breen ME, Dorfman M, Chan SB. Pulmonary embolism despite negative ELISA D-Dimer: A case report. J Emerg Med. 2009;37:290-292.

11. Ray P, Bellick B, Birolleau S, Marx JS, Arock M, Riou B. Referent Ddimer enzyme-linked immunosorbent assay testing is of limited value in the exclusion of thromboembolic disease: result of a practical study in an ED. Am J Emerg Med. 2006;24:313-318.
Vascular Health and Risk Management

\section{Publish your work in this journal}

Vascular Health and Risk Management is an international, peerreviewed journal of therapeutics and risk management, focusing on concise rapid reporting of clinical studies on the processes involved in the maintenance of vascular health; the monitoring, prevention and treatment of vascular disease and its sequelae; and the involvement of

\section{Dovepress}

metabolic disorders, particularly diabetes. This journal is indexed on PubMed Central and MedLine. The manuscript management system is completely online and includes a very quick and fair peer-review system, which is all easy to use. Visit http://www.dovepress.com/ testimonials.php to read real quotes from published authors. 